\title{
Quantitative analysis of adhesion and biofilm formation on hydrophilic and hydrophobic surfaces of clinical isolates of Staphylococcus epidermidis
}

\author{
Nuno Cerca ${ }^{\mathrm{a}}$, Gerald B. Pier ${ }^{\mathrm{b}}$, Manuel Vilanova ${ }^{\mathrm{c}}$, Rosário Oliveira ${ }^{\mathrm{a}}$, Joana Azeredo ${ }^{\mathrm{a}, *}$ \\ ${ }^{a}$ Centro de Engenharia Biológica, Universidade do Minho, Campus de Gualtar, 4710-057 Braga, Portugal \\ ${ }^{\mathrm{b}}$ Channing Laboratory, Department of Medicine, Brigham and Women's Hospital, Harvard Medical School, Boston, MA, USA \\ ${ }^{\mathrm{c}}$ Instituto de Ciências Biomédicas Abel Salazar, Universidade do Porto, Portugal
}

Received 24 May 2004; accepted 11 January 2005

Available online 11 March 2005

\begin{abstract}
Staphylococcus epidermidis is now well established as a major nosocomial pathogen associated with infections of indwelling medical devices. The major virulence factor of these organisms is their ability to adhere to devices and form biofilms. However, it has not been established that adherence and biofilm formation are closely linked phenotypes for clinical isolates. In this study, the initial adhesion to different materials (acrylic and glass) of 9 clinical isolates of $S$. epidermidis, along with biofilm-positive and biofilm-negative control strains, was assayed using physico-chemical interactions to analyze the basis for bacterial adherence to the substratum. X-ray photo electron spectroscopy (XPS) analysis of the cell surface elemental composition was also performed in an attempt to find a relationship between chemical composition and adhesion capabilities. Biofilm formation on the two surfaces was evaluated by dry weight measurements. Human erythrocytes were used to evaluate the ability of $S$. epidermidis strains to cause hemagglutination, an indicator of the production of a poly- $N$-acetyl glucosamine cell surface polysaccharide also involved in biofilm formation. The clinical isolates exhibited different cell wall physico-chemical properties, resulting in differing abilities to adhere to surfaces. Adhesion to hydrophobic substrata for all strains occurred to a greater extent than that to hydrophilic surfaces. Bacterial cell hydrophobicity seemed to have little or no influence on adhesion. X-ray photoelectron spectroscopy analysis showed a high ratio of oxygen/carbon for all strains, which is a common characteristic of S. epidermidis species. No relevant relationship was found between XPS data and adhesion values. All strains forming biofilms were able to agglutinate erythrocytes. However, no direct relationship was found between the amount of biofilm formed and the initial adhesion extent. These results indicate that high levels of initial adherence do not necessarily lead to thick biofilm formation. These two aspects of the pathogenesis of medical device related-infection may need to be evaluated independently to ascertain the contribution of each to the virulence of S. epidermidis causing device-related infections.
\end{abstract}

(c) 2005 Elsevier SAS. All rights reserved.

Keywords: Staphylococcus epidermidis; Adhesion; Biofilms

\section{Introduction}

Staphylococcus epidermidis normally colonizes the human skin and mucous membranes and represents a major component of the normal bacterial flora of this habitat. In

\footnotetext{
* Corresponding author.

E-mail address: jazeredo@deb.uminho.pt (J. Azeredo).
}

predisposed hosts, usually with an indwelling medical device, S. epidermidis has become a significant nosocomial pathogen $[31,34,39,40]$. The major virulence factor associated with this organism's ability to cause infections is dependent on adherence to medical devices and formation of a biofilm [41].

Microbial adhesion to surfaces has been shown to be a complex process, involving physico-chemical, protein and polysaccharide factors $[2,6,7,9,13,16,21,25,26,30]$. From 
an overall physico-chemical point of view, microbial adhesion can be mediated by non-specific interactions, with long-range characteristics, including Lifshitz-van der Waals forces, electrostatic forces, acid-base interactions, and Brownian motion forces [3,37]. As soon as microorganisms reach a surface, they will be attracted or repelled by it, depending on the sum of the different non-specific interactions [17]. In biological systems, hydrophobic interactions are usually the strongest of all long-range noncovalent forces [5], and adhesion to surfaces is often mediated by these types of interactions [35]. It has been demonstrated that hydrophobicity plays an important role in a wide range of microbial infections [15]. Microbial hydrophobicity is defined by the energy of attraction between apolar or slightly polar cells immersed in an aqueous phase [38], and can be assessed by several methods, although, according to Doyle [15], the best method for determining bacterial hydrophobicity is by contact angle measurements.

After initial adhesion, mature biofilm formation is often associated with the production of specific molecules by the microorganisms that mediate cell-to-cell adhesion. In S. epidermidis a polymer of $N$-acetyl glucosamine, initially defined biologically as the polysaccharide intercellular adhesin (PIA) and chemically as Poly- $N$-acetyl-glucosamine (PNAG), have been identified as the molecules responsible for biofilm formation $[10,22,29]$. The PNAG molecule is synthesized from genes contained in the ica locus [12,29]. PNAG/PIA is also involved in the agglutination of erythrocytes, which is a common property of $S$. epidermidis strains $[27,32]$. This characteristic can be used to identify the presence of PNAG/PIA in a S. epidermidis strain by hemagglutination assays.

Expression of PNAG/PIA, adhesion to synthetic surfaces and biofilm formation are virulence factors of $S$. epidermidis clinical strains. As different clinical isolates of $S$. epidermidis are expected to exhibit different phenotypic behaviors $[34,40]$ it is further expected that they might have different capabilities to adhere and to form biofilms on synthetic surfaces.

In this study the ability of 11 strains of $S$. epidermidis to adhere to acrylic (hydrophobic surface) and glass (hydrophilic surface) was determined, as well as the importance of physico-chemical interactions, namely, hydrophobicity, in the adhesion process. The ability to form a mature biofilm, in the same surfaces, was also evaluated, in an attempt to determine if there is a relationship between these two phenomena in clinical isolates of S. epidermidis.

\section{Materials and methods}

\subsection{Bacterial strains}

The S. epidermidis clinical strains used in this work were: IE75, IE186, IE214 (isolated from cases of infective en- docarditis), M129, M187 (isolated from cases of dialysisassociated peritonitis), and FJ6, JI6, LE7 and PE9 (isolated from blood). In addition, we used strain 9142, a known producer of PIA/PNAG, and strain 9142-M10, which has a transposon inserted into the ica locus and does not produce PIA/PNAG. These two strains were provided by D. Mack, Hamburg, Germany.

\subsection{Media and growth conditions}

Tryptic soy broth (TSB) and tryptic soy agar (TSA) plates were prepared according to the manufacturer's instructions. All strains were grown for $24( \pm 2) \mathrm{h}$ at $37^{\circ} \mathrm{C}$ in a shaker rotating at $130 \mathrm{rpm}$ in $15 \mathrm{ml}$ of TSB using bacteria grown on TSA plates not older than 2 days as inocula. Then, $50 \mu$ of each cell suspension was transferred to $30 \mathrm{ml}$ of fresh TSB, which was incubated for $18( \pm 2) \mathrm{h}$ at $37{ }^{\circ} \mathrm{C}$ at $130 \mathrm{rpm}$. After being harvested by centrifugation (for $5 \mathrm{~min}$ at $10500 \mathrm{~g}$ and $4{ }^{\circ} \mathrm{C}$ ), cells were washed twice and resuspended in saline $(0.9 \% \mathrm{NaCl}$ prepared in distilled water) at a concentration of approximately $1 \times 10^{9}$ cells $/ \mathrm{ml}$, determined by the optical density at $640 \mathrm{~nm}$. These cell suspensions were used in the subsequent adhesion and surface characterization assays.

\subsection{Substrate preparation}

Glass was obtained by slicing microscope slides into $2 \times 2 \mathrm{~cm}$ squares. Acrylic was also cut into $2 \times 2 \mathrm{~cm}$ squares. These substrates were immersed in a $0.2 \%$ solution of a commercial detergent overnight, after which they were transferred to a new solution of $0.2 \%$ of the commercial detergent and washed at $40{ }^{\circ} \mathrm{C}$ with strong agitation for $5 \mathrm{~min}$. The squares were then well rinsed with distilled water, and finally each individual square was well rinsed with ultra-pure water and dried at $60^{\circ} \mathrm{C}$, overnight.

\subsection{Physico-chemical characterization of surfaces}

\subsubsection{Bacterial hydrophobicity assay}

The method used for measuring contact angles on bacterial lawns has been described by Busscher et al. [8]. Briefly, a suspension of $S$. epidermidis cells in saline solution was deposited onto a $0.45 \mu \mathrm{m}$ cellulose filter by first washing the filter with $10 \mathrm{ml}$ of distilled water for wetting, and then $20 \mathrm{ml}$ of the cell suspension was added, obtaining a thick lawn of cells after filtration. The lawn of cells was then air-dried for at least $3.5 \mathrm{~h}$, until the so-call "dried-plateau" was obtained. The hydrophobicity parameters were obtained using the sessile-drop contact angle technique, using an automated contact angle device [8]. Contact angles were standardized using as reference liquids: water, formamide and $\alpha$-bromonaphtalene. All experiments were done in duplicates, with 4 repeats. 


\subsubsection{Cell preparation for XPS analysis of the bacteria surface}

X-ray photo electron spectroscopy (XPS) analysis of the elemental composition of the bacterial cells was performed as described by van der Mei et al. [36]. Briefly, fresh cells in TSB $(18 \pm 2 \mathrm{H})$ were harvested and centrifuged for $5 \mathrm{~min}$ at $10500 \mathrm{~g}, 4^{\circ} \mathrm{C}$. Cells were then resuspended in physiological serum at a density of approximately $1 \times 10^{9}$ cells $/ \mathrm{ml}$, and $20 \mathrm{ml}$ of that suspension was filtered through a cellulose filter previously wetted with $10 \mathrm{ml}$ of distilled water. After filtering, the cellulose filter covered with bacteria was sliced into small $1 \mathrm{~cm}^{2}$ squares and quickly frozen in liquid nitrogen. Frozen filters were stored at $-80^{\circ} \mathrm{C}$ for $1-2 \mathrm{~h}$, followed by $24 \mathrm{~h}$ of lyophilization (Christ Alpha 2-4, B. Braun, Germany). The XPS analysis was performed using an ESCALAB 200A apparatus, with a VG5250 software and data analysis. The spectrometer used monochromatized $\operatorname{Mg}(K \alpha)$ $\mathrm{X}$-ray radiation $(15000 \mathrm{eV})$. The constant pass energy of the analyzer was $20 \mathrm{eV}$ and it was calibrated with reference to $\mathrm{Ag} 3 d_{5 / 2}(368.27 \mathrm{eV})$. The pressure during analysis was under $1 \times 10^{-6} \mathrm{~Pa}$. The spectra were recorded following the sequence $\mathrm{C} 1 s, \mathrm{O} 1 s, \mathrm{~N} 1 s, \mathrm{P} 2 p$. The elemental composition was defined as the ratio between oxygen and carbon $(\mathrm{O} / \mathrm{C})$, nitrogen and carbon $(\mathrm{N} / \mathrm{C})$, or phosphorous and carbon $(\mathrm{P} / \mathrm{C})$.

\subsubsection{Substratum surface hydrophobicity}

Cleaned and dried substratum surfaces were used for determining the hydrophobicity parameters of the surface. The hydrophobicity parameters were obtained using the sessiledrop contact angle technique, using an automated contact angle measurement apparatus [8]. Contact angles were standardized using as reference liquids: water, formamide and $\alpha$-bromonaphtalene. All experiments were done in triplicate, with 4 repeats.

\subsection{Adhesion assays}

\subsubsection{Initial adhesion to substrates}

Initial adhesion was performed as described previously [11]. Briefly, squares of acrylic or glass were placed in 6 well tissue-culture plates containing $5 \mathrm{ml}$ of a suspension of $1 \times 10^{9}$ cells $/ \mathrm{ml}$ in saline solution. Initial adhesion to each substratum was allowed to occur for $2 \mathrm{~h}$ at $37^{\circ} \mathrm{C}$, in a shaker rotating at $120 \mathrm{rpm}$. Negative controls were obtained by placing acrylic or glass squares in a saline solution without bacterial cells. The squares were then gently transferred to $100 \mathrm{ml}$ glass beakers containing distilled water, and were allowed to rest there for approximately $10 \mathrm{~s}$. Afterwards, a new transfer was made to a different $100 \mathrm{ml}$ glass beaker with distilled water, followed by a third transfer $10 \mathrm{~s}$ later. These washing steps were carefully performed in order to remove only the cells that were suspended in the liquid interface formed along the surface, and to minimize cell detachment from the surface. The substrate squares with ad- hered cells were dried at $37^{\circ} \mathrm{C}$. All experiments were done in triplicate, with 4 repeats.

\subsubsection{Image analysis}

Before image observation and analysis of adhered cells, the substrate squares were stained with a $0.2 \%$ safranin solution, for better image contrast. Direct bacterial counts were done using a phase contrast microscope coupled to a $3 \mathrm{CCD}$ video camera that acquires images with $820 \times 560$ pixels resolution and at a magnification of $400 \times$. With this magnification $1 \mathrm{~cm}^{2}$ is equivalent to $1.823 \times 10^{4}$ captured images (as determined by a Neubauer chamber). For each surface analyzed, 20 pictures were taken, covering the entire surface. Each image was then analyzed using automated enumeration software, for determining the number of adhering cells.

\subsection{Biofilm assays}

\subsubsection{Biofilm formation on surfaces}

Biofilm formation was performed as described previously [10]. Briefly, clean squares of each type of substrate (glass or acrylic) immersed in distilled water were autoclaved for $15 \mathrm{~min}$ at $121^{\circ} \mathrm{C}$. Each sterilized square was placed in a well of a 6 well tissue-culture plate containing $5 \mathrm{ml}$ of TSB supplemented with $0.25 \%$ of glucose. Then $50 \mu$ of a cell suspension of $1 \times 10^{9}$ cells $/ \mathrm{ml}$ prepared in a $0.9 \% \mathrm{NaCl}$ solution was added. Microbial growth was allowed to occur for $72 \mathrm{~h}$ at $37^{\circ} \mathrm{C}$ while rotating at $120 \mathrm{rpm}$. Every $12 \mathrm{~h}$ the TSB medium containing suspended cells was removed and fresh TSB $+0.25 \%$ glucose was added. Negative controls were obtained by placing sterilized squares in TSB $+0.25 \%$ glucose without adding bacterial cells.

\subsubsection{Biofilm dry-weight determination}

Biofilm dry-weight determinations were performed as described by An and Friedman [1]. Briefly, after $72 \mathrm{~h}$ of growth, the squares were removed from the wells of the tissue culture plates and dried at $80^{\circ} \mathrm{C}$, for $24 \mathrm{~h}$. The squares were weighed and placed again at $80^{\circ} \mathrm{C}$ for 2 more $\mathrm{h}$, and weighed once more to check the stability of the dry weight. Then, the biofilms were scraped from the squares and the dried cell mass weighed. The substrate squares were then further cleaned with $0.2 \%$ of the commercial detergent solution. Cleaned surfaces were dried overnight at $80^{\circ} \mathrm{C}$ and then weighed. Biofilm dry-weights were obtained as the differences between the 2 measurements. All experiments were done in triplicate, with 3 repeats.

\subsection{Hemagglutination assays}

\subsubsection{Erythrocytes}

Human blood collected with heparin was used to retrieve erythrocytes, by adding $5 \mathrm{ml}$ of blood to $45 \mathrm{ml}$ of saline solution which was then centrifuged twice at $2500 \mathrm{~g}$ for $10 \mathrm{~min}$. Next, $100 \mu \mathrm{l}$ of the pellet was added to $10 \mathrm{ml}$ of a saline so- 
lution, obtaining a $1 \%$ erythrocyte solution to be used in the hemagglutination assays.

\subsubsection{Hemagglutination assays}

The hemagglutination assay was performed as described elsewhere [27] with some modifications. Briefly, S. epidermidis cells from an overnight culture in TSB were grown in fresh TSB supplemented with $0.25 \%$ glucose for $18 \mathrm{~h}$. Cells were then resuspended in saline, and adjusted to a concentration of approximately $3 \times 10^{9}$ cells $/ \mathrm{ml}$. Five twofold dilutions of each cell suspension were made $(100 \mu \mathrm{l})$ in 96 well (U-shaped) microtiter plates. Then $100 \mu \mathrm{l}$ of the $1 \%$ erythrocyte solution was added to each well. To ensure thorough mixing of the bacteria and erythrocytes, the total volume of each well was pipetted in and out with a micropipette. Incubation was at room temperature for $2 \mathrm{~h}$, and hemagglutination titers were evaluated macroscopically. Erythrocytes that appeared to be negative for macroscopic hemagglutination were also evaluated microscopically. All experiments were done in duplicate with 3 repeats.

\subsection{Statistical analysis}

All the assays were compared using one-way analysis of variance (ANOVA) by applying Levene's test of homogeneity of variances and the Tukey multiple comparisons test, and also the paired sample $t$-test, using SPSS software (Statistical Package for the Social Sciences). Student's $t$-test was applied to all experimental data for rejection of some experimental values. All tests were performed with a confidence level of $95 \%$.

\section{Results}

\subsection{Surface physico-chemical analysis}

Bacterial cell surface physico-chemical characteristics are presented in Table 1. Water contact angles formed by bacterial lawns can be used as a qualitative indication of cell surface hydrophobicity, with lower values indicating a more hydrophilic surface. The values obtained for all strains assayed were quite similar, ranging from contact angles of $19.9^{\circ}$ (strain 9142-M10) to $33.7^{\circ}$ (strain M187), indicating that these different bacterial strains have comparable levels of cell surface hydrophobicity. All clinical S. epidermidis strains examined here could be considered hydrophilic. From Table 1 it can also be observed that all strains had surfaces that were predominantly electron donors (higher values of $\gamma_{S}^{-}$), with a low electron acceptor parameter $\left(\gamma_{S}^{+}\right)$. The exception was strain IE214 that had the greatest electron acceptor parameter. Interestingly, under the growth conditions used in this study this strain grew as highly aggregated cells, forming a flocculent suspension in the growth medium.
Table 1

Water contact angle (in degrees) of $S$. epidermidis strains, and cell surface hydrophobicity parameters (in $\mathrm{mJ} / \mathrm{m}^{2}$ )

\begin{tabular}{|c|c|c|c|c|c|}
\hline Strain & $\begin{array}{l}\text { Water contact angle } \\
( \pm \mathrm{SD})\end{array}$ & $\gamma_{\mathrm{S}}^{\mathrm{LW}}$ & $\gamma_{\mathrm{S}}^{+}$ & $\gamma_{S}^{-}$ & $\Delta G_{\text {iwi }}^{\mathrm{TOT}}$ \\
\hline 9142 & 26.1 (1.6) & 29.07 & 4.32 & 43.79 & 17.59 \\
\hline 9142-M10 & $19.9(1.5)$ & 28.82 & 4.66 & 47.09 & 19.97 \\
\hline IE75 & $26.8(2.8)$ & 26.63 & 5.06 & 43.83 & 17.10 \\
\hline IE186 & $19.6(2.0)$ & 27.53 & 5.12 & 47.37 & 19.75 \\
\hline IE214 & $18.7(0,9)$ & 19.51 & 8.96 & 48.44 & 15.58 \\
\hline M129 & $28.5(2.6)$ & 28.67 & 4.73 & 41.16 & 14.76 \\
\hline M187 & 33.7 (1.6) & 27.63 & 4.93 & 37.49 & 11.45 \\
\hline FJ6 & $30.1(3.8)$ & 30.15 & 3.73 & 41.42 & 15.94 \\
\hline JI6 & $28.8(5.1)$ & 28.43 & 4.86 & 40.84 & 14.36 \\
\hline LE7 & $25.1(3.8)$ & 31.21 & 3.45 & 45.04 & 19.52 \\
\hline PE9 & $29.7(1.2)$ & 30.29 & 3.72 & 41.61 & 16.08 \\
\hline
\end{tabular}

SD means standard deviation; $\gamma_{\mathrm{S}}^{\mathrm{LW}}$ represents the apolar Lifshitz-van der Waals surface free energy component; $\gamma_{S}^{+}$represents the electron acceptor surface free energy component; $\gamma_{\mathrm{S}}^{-}$represents the electron donator surface free energy component; $\Delta G_{\text {iwi }}^{\mathrm{TOT}}$ represents the degree of hydrophobicity.

Table 2

Water contact angle (in degrees) of the substratum, and surface hydrophobicity parameters (in $\mathrm{mJ} / \mathrm{m}^{2}$ )

\begin{tabular}{|c|c|c|c|c|c|}
\hline Surface & $\begin{array}{l}\text { Water contact angle } \\
( \pm \mathrm{SD})\end{array}$ & $\gamma_{\mathrm{S}}^{\mathrm{LW}}$ & $\gamma_{\mathrm{S}}^{+}$ & $\gamma_{\mathrm{S}}^{-}$ & $\Delta G_{\text {iwi }}^{\mathrm{TOT}}$ \\
\hline Glass & $23.0(2.2)$ & 34.53 & 2.72 & 45.46 & 19.98 \\
\hline Acrylic & $85.5(2.2)$ & 38.06 & 0 & 7.59 & -50.82 \\
\hline
\end{tabular}

SD means standard deviation; $\gamma_{\mathrm{S}}^{\mathrm{LW}}$ represents the apolar Lifshitz-van der Waals surface free energy component; $\gamma_{S}^{+}$represents the electron acceptor surface free energy component; $\gamma_{\mathrm{S}}^{-}$represents the electron donator surface free energy component; $\Delta G_{\text {iwi }}^{\mathrm{TOT}}$ represents the degree of hydrophobicity.

Table 3

Bacterial surface elemental composition of cells grown in TSB during $18 \mathrm{H}$ at $37^{\circ} \mathrm{C}$

\begin{tabular}{llll}
\hline Strain & N/C & O/C & P/C \\
\hline 9142 & 0.203 & 0.479 & 0.042 \\
9142-M10 & 0.189 & 0.530 & 0.046 \\
IE75 & 0.195 & 0.408 & 0.038 \\
IE186 & 0.193 & 0.463 & 0.041 \\
IE214 & 0.197 & 0.420 & 0.028 \\
M129 & 0.187 & 0.502 & 0.050 \\
M187 & 0.200 & 0.408 & 0.030 \\
FJ6 & 0.171 & 0.539 & 0.054 \\
JI6 & 0.173 & 0.570 & 0.055 \\
LE7 & 0.202 & 0.513 & 0.048 \\
PE9 & 0.192 & 0.473 & 0.041 \\
\hline
\end{tabular}

Substrate surface physico-chemical characteristics are presented in Table 2. Water contact angles of the 2 materials used clearly differed, with glass being hydrophilic, as expected (water contact angle of $23.0^{\circ}$ and $\Delta G_{\text {iwi }}^{\mathrm{TOT}}>0$ ) and acrylic being hydrophobic (water contact angle of $85.5^{\circ}$ and $\left.\Delta G_{\text {iwi }}^{\mathrm{TOT}}<0\right)$.

The elemental composition of the surface of the bacterial strains, determined by XPS, is given in Table 3. All strains used in this study exhibited high $\mathrm{O} / \mathrm{C}$ values, ranging from 


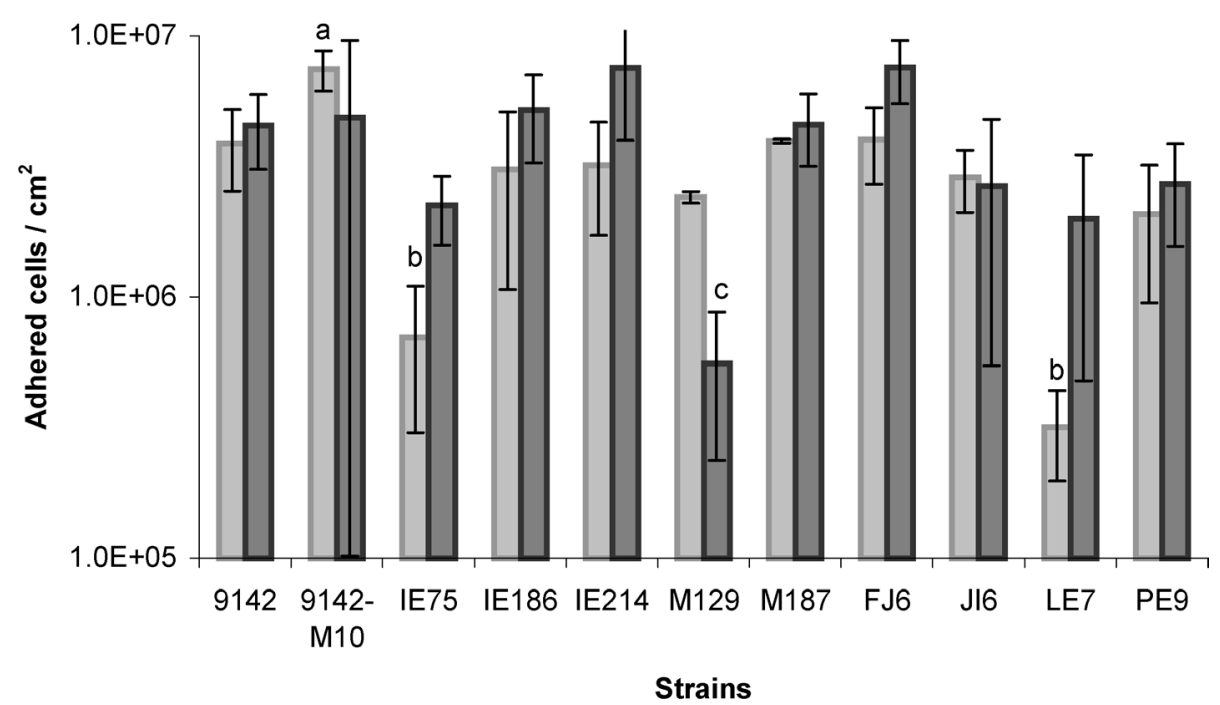

Fig. 1. Differences in adhesion of S. epidermidis strains to glass ( $\square$ ) and acrylic ( $\square)$. (a) Strain with high extent of adhesion to glass $(P<0.05)$; (b) strain with low extent of adhesion to glass $(P<0.05)$; (c) strain with low extent of adhesion to acrylic $(P<0.05)$.

0.408 (strain M187) to 0.570 (strain J16). On the other hand, $\mathrm{P} / \mathrm{C}$ values were low, ranging from only 0.028 (strain IE214) to 0.055 (strain JI6).

\subsection{Initial binding to substratum}

Initial binding of bacteria to both substrate surfaces is presented in Fig. 1. A wide range in the number of bound cells was obtained, ranging from $3.19 \times 10^{5}$ cells $/ \mathrm{cm}^{2}$ (strain LE7 on glass) to $7.55 \times 10^{6}$ cells $/ \mathrm{cm}^{2}$ (strain FJ6 on acrylic). For 8 of 11 strains the number of bacterial cells initially bound to glass was lower when compared to acrylic $(P<0.05$, paired- $t$-test). Strains $9142-$ M10, M129 and JI6 were the exceptions, with the latter not showing a significant difference in binding to the two substrates $(P<0.05$, paired- $t$-test).

Strain 9142-M10 had the highest initial binding to glass $\left(7.4 \times 10^{6}\right.$ cells $\left./ \mathrm{cm}^{2}\right)$, whereas strains LE7 and IE75 had low initial binding to glass $\left(3.2 \times 10^{5}\right.$ and $7.0 \times 10^{5}$ cells $/ \mathrm{cm}^{2}$ respectively), making these phenotypes markedly different from the remaining strains $(P<0.05$, ANOVA and Tukey's multiple comparison test). When binding to acrylic, strain M129 can be considered a low binding strain $\left(5.6 \times 10^{5}\right.$ cells $\left./ \mathrm{cm}^{2}\right)$, being markedly different from most of the remaining strains $(P<0.05$, ANOVA and Tukey's multiple comparison test).

\subsection{Hemagglutination assays}

Most strains were able to agglutinate human erythrocytes (Table 4); however as can be seen by the titers, the overall degree of hemagglutination activities was relatively weak. Bacterial dilutions from a standardized initial amount that causes hemagglutination ranged from 1:1 (strain LE7) to 1:16 (strain IE214). Strains 9142-M10 and IE75 did not cause any agglutination of human erythrocytes. For those
Table 4

Hemagglutination macroscopic titers and microscopic confirmation of S. epidermidis strains

\begin{tabular}{lll}
\hline Strain & Hemagglutination titers & Microscopic observation \\
\hline 9142 & $1: 2$ & - \\
9142-M10 & No hemagglutination & No hemagglutination \\
IE75 & No hemagglutination & Hemagglutination observed \\
IE186 & $1: 4$ & - \\
IE214 & $1: 16$ & - \\
M129 & $1: 2$ & - \\
M187 & $1: 4$ & - \\
FJ6 & $1: 2$ & - \\
J66 & $1: 8$ & - \\
LE7 & $1: 1$ & - \\
PE9 & $1: 8$ & - \\
\hline
\end{tabular}

strains, microscopic observations of the suspension containing bacterial cells and erythrocytes were performed. With this observation, strain IE75 microagglutinated the erythrocytes, whereas the ica-interrupted strain 9142-M10 did not induce any hemagglutination.

\subsection{Biofilm formation}

The amount of biofilm formed on both the glass and acrylic substrate surfaces is presented in Fig. 2. Most of the strains were able to form biofilms on both materials tested, except for the ica-interrupted strain 9142-M10, which was used as a negative control for biofilm formation. It was observed that only a small amount of biofilm was formed by strain IE75 on both materials. The amount of biofilm produced by almost all of the other strains on acrylic surfaces was greater than on glass. The only exception was strain PE9. Therefore, a hydrophobic surface appears to promote biofilm formation by most clinical isolates of S. epidermidis.

Strains 9142, IE186, JI6 and PE9 showed significantly different abilities from the remaining strains to form biofilms 


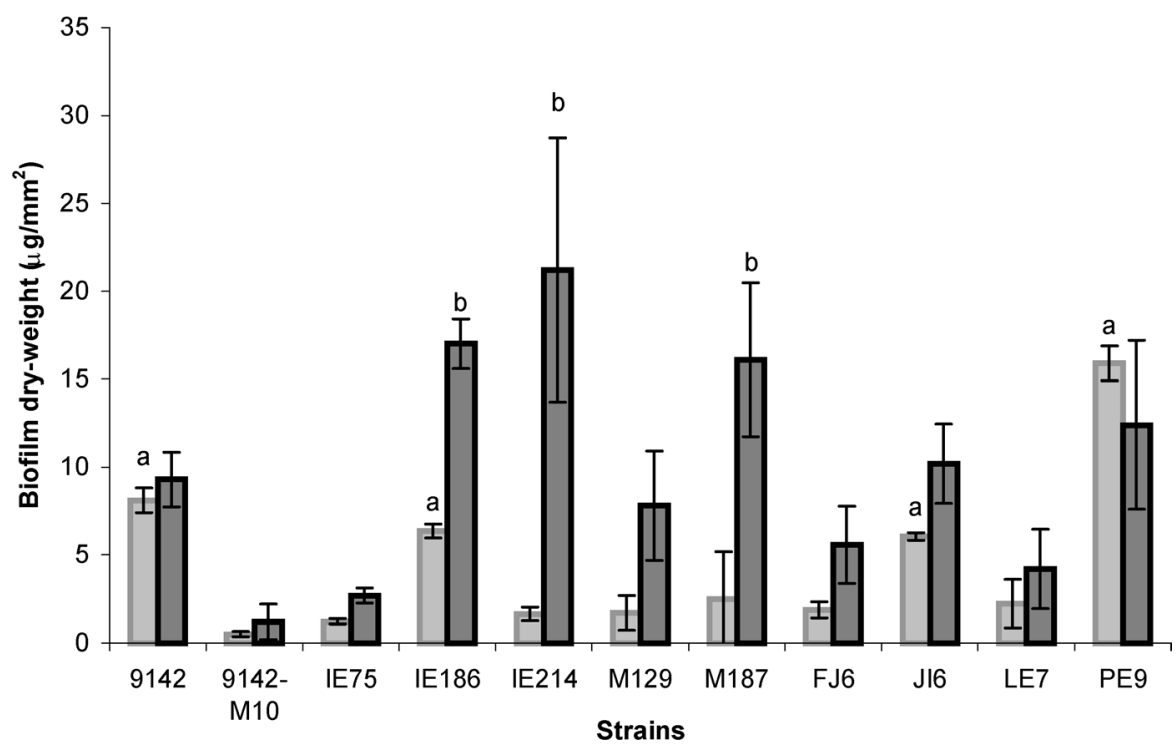

Fig. 2. Biofilm formation of S. epidermidis strains on glass $(\square)$ and acrylic ( $\square$ ). (a) High biofilm producers on glass $(P<0.05)$; (b) high biofilm producers on acrylic $(P<0.05)$.

on glass $\left(8.2,6.4,6.0\right.$ and $15.0 \mu \mathrm{g} / \mathrm{mm}^{2}$, respectively), being considered high biofilms producers on glass $(P<0.05$, ANOVA and Tukey's multiple comparison test). On acrylic, strains IE186, IE214 and M187 were the highest biofilm producers (16.9, 20.9 and $16.1 \mu \mathrm{g} / \mathrm{mm}^{2}$, respectively), being markedly different from most of the remaining strains $(P<0.05$, ANOVA and Tukey's multiple comparison test). Since only one strain, IE186, was a high biofilm producer on both surfaces it appeared that different clinical isolates have differing abilities to form biofilms on hydrophobic versus hydrophilic surfaces.

\section{Discussion}

S. epidermidis is now recognized to be one of the most common causes of serious nosocomial infections [39], and this is related to the organism's ability to adhere to indwelling medical devices and form biofilms on them [41]. Bacterial adhesion is thought to be the first of two steps of biofilm formation $[10,41]$, the second stage being accumulation of the bacterial cells in the biofilm mass. Biofilms play an important role in implant infections such as catheters [40], voice prostheses [7] and also bone-cement implants, intraocular artificial lens and cranioploastic implants [14].

In this study, we first evaluated the adherence of 9 clinical S. epidermidis strains along with an isogenic pair of strains with one lacking an intact ica locus to 2 different substrata using a static adhesion assay. This methodology of assessing adherence has been controversial due to the use of washing steps necessary to remove non-adherent and loosely adherent cells [4]. It has been demonstrated that the passage of an air-liquid interface through a lawn of adherent bacteria can detach some of the cells [19], although this effect is attenuated in the presence of a more hydrophilic substrate or with more rapid washing of adherent cells [20]. In a previous study [13], several different washing procedures were assayed and the effect of each was evaluated as reported by Suárez et al. [19]. The results obtained suggested that when using hydrophilic glass no effect is observed from the different washing procedures. Conversely, for the hydrophobic acrylic substrate, an effect was sometimes observed, but was attenuated by rapid washing to minimize the time of exposure of the adherent cells to the air-liquid interface.

As expected, the clinical isolates exhibited differing abilities to adhere to the substrate surfaces and form biofilms. A quantitative value of hydrophobicity, expressed in International System (SI) units, can be obtained through the van Oss approach $[37,38]$. According to this theory hydrophobicity is defined as the free energy of interaction between two entities (i) when immersed in water (w) $-\Delta G_{\text {iwi }}$. If $\Delta G_{\text {iwi }}<0$, there is a preferential interaction between entities (i) rather than between an entity (i) and water, and the substance (i) is considered hydrophobic. By the same reasoning, if $\Delta G_{\text {iwi }}>0$ the substance (i) is hydrophilic. For all strains used in this study, the highest level of initial binding occurred when the hydrophobic acrylic $\left(\Delta G_{\text {iwi }}^{\mathrm{TOT}}=\right.$ $-50.82 \mathrm{~mJ} / \mathrm{m}^{2}$ ) was used as a substratum, whereas a lower level of initial binding was generally obtained with the hydrophilic glass $\left(\Delta G_{\mathrm{iwi}}^{\mathrm{TOT}}=19.98 \mathrm{~mJ} / \mathrm{m}^{2}\right)$. Clearly, substratum hydrophobicity greatly influences the initial binding of S. epidermidis, a result implicated in other studies but never fully examined with a range of clinical isolates of this organism.

However, no relationship was found between the bacterial strain's surface hydrophobicity and the extent of initial binding to either a hydrophilic or hydrophobic substrate. For instance, strain FJ6 exhibited one of the lowest hydrophilic surfaces (water contact angle of $30.1^{\circ}$ ) but was also one of the strains with high initial binding to the substrata. Con- 
versely, strain IE214 had the highest hydrophilic surface (water contact angle of $18.7^{\circ}$ ) and was also one of the strains with high initial binding to the substrata. These findings are similar to those of other authors $[7,13,30]$.

Strain IE214 had the greatest electron acceptor parameter (Table 1). Interestingly, under the growth conditions used in this study, this strain grew as highly aggregated cells, forming a flocculent suspension in the growth medium This can be explained by both higher electron acceptor and donor parameters, meaning that this strain can establish a great number of acid-base interactions between one cell and another [37].

Many prior studies suggested that hydrophobic interactions contribute to the initial binding of pathogens to tissues, leading to colonization, invasion or tissue destruction [15]. A microorganism may adhere to a substratum via the hydrophobic effect if the associating sites possess sufficiently high densities of apolar areas [15]. Compared to glass, acrylic has such high densities of apolar areas, as can be seen by $\gamma_{S}^{-}$and $\gamma_{S}^{+}$values presented in Table 2 , and the bacteria bound better to this substrate than to glass. Thus, $S$. epidermidis microorganisms may be more prone to binding to hydrophobic surfaces such as acrylic compared to glass.

It is generally accepted that the outermost cell surface plays a crucial role in bacterial binding to surfaces, as it interacts directly with the substratum surface $[6,36]$. In an attempt to correlate adhesion results with surface elemental composition, XPS analysis of the cell surface was performed. The ratios $\mathrm{O} / \mathrm{C}, \mathrm{N} / \mathrm{C}$ and $\mathrm{P} / \mathrm{C}$ of the various strains studied were in the same range of values reported by Van der Mei et al. [36]. In their study, a cluster analysis of 210 microbial strains, including 33 staphylococci, revealed that $\mathrm{O} / \mathrm{C}$ values for staphylococci are very high, ranging from 0.355 to 0.638 [36]. It has been suggested that high $\mathrm{O} / \mathrm{C}$ may be an indicator of capsular polysaccharide material on the outer membrane [36]. No relation was found between the extent of adhesion and XPS data. Nevertheless, N/C values can be correlated with cell surface hydrophobicity-less hydrophobic cells exhibited lower N/C.

In order to determine whether the initial adhesion event was a determinant of the subsequent amount of biofilm formed, biofilm dry weights were obtained on the same substrates used in the initial binding experiments. Several prior studies evaluated biofilm formation on the bottom of U-shaped polystyrene microtiter plates [10,22,23,27,29], but such studies did not consider the influence of different substrates on biofilm formation [29]. Furthermore, by weighing the dried biofilm mass, a direct quantitative comparison of biomass formation by different strains could be made. In the present study, no direct relationship between the ability of strains to initially bind and subsequently form biofilms was found. For instance, strains IE75, M129 and JI6 had comparable initial binding levels; however, while the last 2 formed relatively thick biofilms, IE75 hardly formed more than a monolayer. This result indicates that biofilm formation is not dependent on the extent of initial adherence of bacteria to the substrate. In a study with 54 clinical isolates, a qualitative analysis of biofilm formation was performed and similar conclusions were withdrawn [18]. However, the study conducted here provides more detailed information because it is based on a quantitative analysis of biofilm formation and thus it makes it possible to obtain a better evaluation of the relationship between initial binding and biofilm formation. Heilmann et al. demonstrated in 1996, that biofilm formation and initial adhesion were two distinct phenomena, using one mutant S. epidermidis strain [23]. However, a recent study by Maira-Litran et al. [28] demonstrated that the original conclusions from Heilmann et al. [22] reporting adherence and biofilm formation on polystyrene plates, was dependent on the manufacturer of the plates, since different results obtained with the exact same strains and using the exact same methodology were obtained with plates made in the US compared with those made in Germany.

Biofilm formation is more likely to be dependent on cellto-cell adhesion rather than on the amount of cells initially attached to the surface. As no relationship between cell surface properties and biofilm formation was found, cell-to-cell adhesion is probably established by specific interactions and not influenced by the physico-chemical interactions of the bacteria with the attachment substrate. Likely, adherence is a complex phenomenon involving a variety of surface factors on the bacterium. One such factor, that has been proposed is the $S$. epidermidis autolysin encoded by the atlE gene [24]. However, while an atlE mutant was deficient in attachment to polystyrene and this was restored in a complemented strain, it was never definitively shown in this study that it was the atlE protein itself, and not a secondary effect of the atlE mutation, such as disruption in PNAG/PIA production, that caused the defect in adherence.

PNAG/PIA can also agglutinate erythrocytes [32] and a direct relationship was found between the ability of a strain of $S$. epidermidis to agglutinate erythrocytes and to form a biofilm. For 9 of the 11 strains, a linear relation was derived describing the relationship between biofilm formation (B) and hemagglutination titers $(\mathrm{T}): \mathrm{B}=1.0807 \times \mathrm{T}+3.6025$, $r=0.9054$. For instance, strain IE214 formed the greatest amount of biofilm $\left(21.2 \mu \mathrm{g} / \mathrm{mm}^{2}\right.$ on acrylic) and exhibited the highest hemagglutination titer (1:16). Conversely, strain IE75 formed small amounts of biofilm on both surfaces (1.2 on glass and $2.7 \mu \mathrm{g} / \mathrm{mm}^{2}$ on acrylic) and no macroscopic hemagglutination was observed, for this strain. However, via microscopic examination, it was possible to verify that strain IE75 could bind to human erythrocytes and cause some degree of agglutination. As expected, strain 9142-M10, the biofilm-negative control strain, did not agglutinate human erythrocytes because this strain cannot express PNAG/PIA [27]. Probably the clinical isolate IE75 expressed small amounts of PNAG/PIA, giving rise to both low biofilm formation and small hemagglutination capabilities, but the amount of PNAG/PIA produced by this strain was not formally quantified. Taking together hemagglutination data 
that reflect the level of expression of PNAG/PIA, although it may not be entirely quantitative, it is possible to conclude that PNAG/PIA is a clear determinant of biofilm formation, but not for initial adhesion of $S$. epidermidis under the conditions studied. However, using shorter-term adherence assays to catheters, it has been found that PNAG/PIA contributes to adherence in this setting [30], emphasizing the effect of test conditions on the outcomes obtained.

Overall, it also appears from our studies that there is a wide range of variation in adherence and biofilm formation among clinical S. epidermidis strains. For instance, the number of adherent cells of clinical strain LE7 was 23 times lower than that of ica-interrupted strain 9142-M10 (on glass) and the number of adherent cells of clinical strain M129 was 13 times lower than that of clinical strain FJ6 (on acrylic). Strain IE214 formed a biofilm almost 8 times greater than that of strain IE75 and 5 times greater than that of strain LE7 (on acrylic). Thus, initial adhesion and biofilm formation on inert surfaces, which are considered to be manifestations of one of the major virulence factors of S. epidermidis, are strain-dependent and not a consistent phenotypic characteristic of the species or of clinical isolates. This means that when evaluating either bacterial adherence or biofilm formation, it is important to take into account that the relative levels of these phenotypes do not reflect the potential of the organism to cause a clinically significant infection. Obviously, host factors associated with susceptibility to infection make a major contribution to the outcome of an infectious process, and this cannot be determined by measuring bacterial phenotypes. Therefore, it might be important to consider that properties of PNAG/PIA unrelated to bacterial adherence and biofilm formation, such as providing resistance of the bacteria to host immune effectors $[33,42]$, may be important in the outcome of an S. epidermidis infection.

\section{Acknowledgements}

The authors acknowledge the financial support of FCT, through the project FCT POCTI/ESP/42688/2001, and also grant SFRH/BD/8676/2002. G.B.P. was supported by NIH grant AI 46706.

\section{References}

[1] Y. An, R. Friedman, Laboratory methods for studies of bacterial adhesion, J. Microbiol. Meth. 30 (1997) 141-152.

[2] J. Azeredo, R. Oliveira, The role of exopolymers in the attachment of Sphingomonas paucimobilis, Biofouling 61 (2000) 59-67.

[3] J. Azeredo, R. Oliveira, in: P. Lens, A.P. Moran, T. Mahoney, P. Stoodley, V. O'Flaherty (Eds.), Biofilms in Medicine, Industry and Environmental Biotechnology-Characteristics, Analysis and Control, IWA Publishing, London, 2003, pp. 16-31.

[4] R. Bos, H. van der Mei, H. Busscher, Physico-chemistry of initial microbial adhesive interactions - its mechanisms and methods for study, FEMS Microbiol. Rev. 23 (1999) 179-230.

[5] R. Briandet, J. Herry, M. Bellon-Fontaine, Determination of the van der Waals, electron donor and electron acceptor surface tension com- ponents of static Gram-positive microbial biofilms, Colloids Surf. B Biointerfaces 21 (2001) 299-310.

[6] G. Bruinsma, H. van der Mei, H. Bussher, Bacterial adhesion to surface hydrophilic and hydrophobic contact lenses, Biomaterials 22 (2001) 3217-3224.

[7] H. Busscher, G. Geertsema-Doornbusch, H. van der Mei, Adhesion to silicone rubber of yeast and bacteria isolated from voice prostheses: Influence of salivary conditioning films, J. Biomed. Mat. Res. 34 (1997) 201-210.

[8] H. Busscher, A. Weerkamp, H. van der Mei, A. van Pelt, H. De Jong, J. Arends, Measurement of the surface free-energy of bacterial-cell surfaces and its relevance for adhesion, Appl. Environ. Microbiol. 48 (1984) 980-983.

[9] H. Busscher, A. Weerkamp, Specific and non-specific interactions in bacterial adhesion to solid substrata, FEMS Microbiol. Rev. 46 (1987) $165-173$.

[10] N. Cerca, G.B. Pier, M. Vilanova, R. Oliveira, J. Azeredo, Influence of batch or fed-batch growth on Staphylococcus epidermidis biofilm formation, Lett. Appl. Microbiol. 39 (2004) 420-424.

[11] N. Cerca, G.B. Pier, R. Oliveira, J. Azeredo, Comparative evaluation of coagulase-negative staphylococci (CoNS) adherence to acrylic by a static method and a parallel-plate flow dynamic method, Res. Microbiol. 155 (2004) 755-760.

[12] S. Cramton, C. Gerke, N. Schnell, W. Nichols, F. Gotz, The intercellular adhesion (ica) locus is present in Staphylococcus aureus and is required for biofilm formation, Infect. Immun. 67 (1999) 5427-5433.

[13] D. Cunliffe, C. Smart, C. Alexander, E. Vulfson, Bacterial adhesion at synthetic surfaces, App. Environ. Microb. 65 (1999) 4995-5002.

[14] J. Dankert, A.H. Hogt, J. Feijen, Biomedical polymers: Bacterial adhesion, colonization and infection, CRC Crit. Rev. Biocomp. 2 (1986) 219-301.

[15] R. Doyle, Contribution of the hydrophobic effect to microbial infection, Microb. Infect. 2 (2000) 391-400.

[16] W. Dunne Jr., Bacterial adhesion: Seen any good biofilms lately?, Clinic. Microbiol. Rev. 15 (2003) 155-166.

[17] A. Fonseca, P. Granja, J. Nogueira, R. Oliveira, Staphylococcus epidermidis RP62A adhesion to chemically modified cellulose derivatives, J. Mater. Sci. Mat. Med. 12 (2001) 543-548.

[18] J. Galdbart, J. Allignet, H.S. Tung, C. Rydèn, N.E. Solh, Screening for Staphylococcus epidermidis markers discriminating between skinflora strains and those responsible for infections of joint prostheses, J. Infect. Dis. 182 (2000) 351-355.

[19] C. Gómez-Suárez, H. Busscher, H. Van der Mei, Analysis of bacterial detachment from substratum surfaces by the passage of air-liquid interfaces, Appl. Environ. Microbiol. 67 (2001) 2531-2537.

[20] C. Gómez-Suárez, J. Noordmans, H. van der Mei, H. Busscher, Detachment of colloidal particles from collector surfaces with different electrostatic charge and hydrophobicity by attachment to air bubbles in a parallel plate flow chamber, Phys. Chem. 1 (1999) 4423-4427.

[21] M. Gross, S. Cramnton, F. Gotz, A. Peschel, Key role of teichoic acid net charge in Staphylococcus aureus colonization of artificial surfaces, Infect. Immun. 69 (2001) 3423-3426.

[22] C. Heilmann, C. Gerke, F. Perdreau-Remington, F. Gotz, Characterization of Tn917 insertion mutants of Staphylococcus epidermidis affected in biofilm formation, Infect. Immun. 64 (1996) 277-282.

[23] C. Heilmann, O. Schweitzer, C. Gerke, N. Vanittanakon, D. Mack, F. Gotz, Molecular basis of intercellular adhesion in the biofilmforming Staphylococcus epidermidis, Mol. Microbiol. 20 (1996) 1083-1091.

[24] C. Heilmann, M. Hussain, G. Peters, F. Gotz, Evidence for autolysinmediated primary attachment of Staphylococcus epidermidis to a polystyrene surface, Mol. Microbiol. 5 (1997) 1013-1024.

[25] B. Jucker, H. Harms, A. Zehnder, Adhesion of the positively charged bacterium Stenotrophomonas (Xanthomonas) maltophilia 70401 to glass and Teflon, J. Bacteriol. 78 (1996) 5472, 5479.

[26] R. Koerner, L. Butterworth, I. Mayer, R. Dasbach, H. Busscher, Bacterial adhesion to titanium-oxynitride (TiNOX) coatings with different 
resistivities: A novel approach for the development of biomaterials, Biomaterials 23 (2002) 2835-2840.

[27] D. Mack, J. Riedwald, H. Rohde, T. Magnus, H. Feucht, H. Elsner, R. Laufs, M. Rupp, Essential functional role of the polysaccharide intercellular adhesin of Staphylococcus epidermidis in hemagglutination, Infect. Immun. 67 (1999) 1004-1008.

[28] T. Maira-Litra, A. Kropec, D. Goldmann, G. Pier, Biologic properties and vaccine potential of the staphylococcal poly- $N$-acetyl glucosamine surface polysaccharide, Vaccine 22 (2004) 872-879.

[29] D. McKenney, J. Hubner, E. Muller, Y. Wang, D. Goldmann, G. Pier, The ica locus of Staphylococcus epidermidis encodes production of the capsular polysaccharide/adhesin, Infect. Immun. 66 (1998) 47114720.

[30] N. Mohamed, M. Teeters, J. Patti, M. Hook, J. Ross, Inhibition of Staphylococcus aureus adherence to collagen under dynamic conditions, Infect. Immun. 67 (1999) 589-594.

[31] J. O'Gara, H. Humphreys, Staphylococcus epidermidis biofilms: Importance and implications, J. Med. Microbiol. 50 (2001) 582-587.

[32] M. Rupp, G. Archer, Hemagglutination and adherence to plastics by Staphylococcus epidermidis, Infect. Immun. 60 (1992) 4322-4327.

[33] H. Shiro, E. Muller, N. Gutierrez, S. Boisot, M. Grout, T. Tosteson, D. Goldmann, G. Pier, Transposon mutants of Staphylococcus epidermidis deficient in elaboration of capsular polysaccharide/adhesin and slime are avirulent in a rabbit model of endocarditis, J. Infect. Dis. 5 (1994) 1042-1049.

[34] D. Souvenir, D. Anderson Jr., S. Palpant, H. Mroch, S. Askin, J. Anderson, J. Claridge, J. Eiland, C. Malone, M. Garrison, P. Watson, D. Campbell, Blood Cultures positive for coagulase-negative staphylo- cocci: Antisepsis, pseudobacteremia and therapy of patient, J. Clinic. Microbiol. 36 (1998) 1923-1926.

[35] P. Teixeira, R. Oliveira, Influence of surface characteristics on the adhesion of Alcaligenes denitrificans to polymeric substrates, J. Adh. Sci. Technol. 13 (1999) 1287-1294.

[36] C. van der Mei, J. De Vries, H.J. Busscher, X-ray photoelectron spectroscopy for the study of microbial cell surfaces, Surf. Sci. Rep. 39 (2000) 1-24.

[37] C. van Oss, Hydrophobicity of biosurfaces-origin, quantitative determination and interaction energies, Colloids Surf. B. 5 (1995) 91110.

[38] C. van Oss, R. Giese, The hydrophilicity and hydrophobicity of clay minerals, Clay Miner. 43 (1995) 474-477.

[39] C. Vermont, N. Hartwig, A. Fleer, P. de Man, H. Verbrugh, J. van der Anker, R. de Groot, A. van Belkun, Persistence of clones of coagulasenegative staphylococci among premature neonates in neonatal intensive care units: Two-center study of bacterial genotyping and patient risk factors, J. Clinic. Microbiol. 36 (1998) 2485-2490.

[40] D. de Viedma, P. Rabadan, M. Díaz, E. Cercenado, E. Bouza, Heterogeneous antimicrobial resistance patterns in polyclonal populations of coagulase-negative staphylococci isolated from catheters, J. Clinic. Microbiol. 34 (2000) 1359-1363.

[41] C. Voung, M. Otto, Staphylococcus epidermidis infections, Microb. Infect. 4 (2002) 481-489.

[42] C. Voung, J.M. Voyich, E.R. Fischer, K.R. Braughton, A.R. Whitney, F.R. DeLeo, M. Otto, Polysaccharide intercellular adhesin (PIA) protects Staphylococcus epidermidis against major components of the human innate immune system, Cell Microbiol. 6 (2004) 269-275. 